\title{
Reproductive mortality
}

\author{
VALERIE BERAL
}

British Medical fournal, 1979, 2, 632-634

\section{Summary and conclusions}

The transfer from traditional to modern methods of contraception in recent decades has been accompanied by a transfer of deaths from complications of pregnancy to deaths from complications of the modern contraceptive methods. In 1975, for example, it is estimated that there were more deaths at ages 25-44 years in England and Wales from adverse effects of oral contraceptive use than from all complications of pregnancy, delivery, and the puerperium combined. Thus maternal mortality is no longer an adequate indicator of the deaths associated with reproduction in the community. An alternative measure, the reproductive mortality rate should be used, which includes deaths from complications of contraceptive use as well as those from complications of pregnancy or abortion.

The reproductive mortality rate in England and Wales seems to have declined continuously since 1950 for women aged 25-34. But after 1960 it increased for women aged 35-44, because of the higher mortality associated with oral contraceptive use in this age group.

\section{Introduction}

Maternal mortality has long been regarded as an important indicator of the health of women in relation to their reproductive practices. Maternal mortality has fallen considerably, with the death rate from complications of pregnancy, childbirth, and the puerperium in England and Wales now being less than one-twentieth of what it was 100 years ago. ${ }^{1}$ Reasons for this impressive decline in mortality include advances in antenatal and obstetric care, improvements in the general health of pregnant women, the legalisation of abortion, and the increasing tendency for women to have small families and to complete their childbearing at relatively young ages.

The declining birth rates and maternal mortality rates have also been associated with radical changes in the availability and use of different methods of birth control. Since the 1960 s "modern" methods of contraception, particularly oral contraceptives and the intrauterine contraceptive device (IUCD), have become increasingly popular. ${ }^{2}{ }^{3}$ These new contraceptives may have adverse effects on health and may occasionally be fatal. ${ }^{5}$ Because over a third of women of childbearing age in England and Wales use one or other of these two methods of contraception, ${ }^{3}$ we need to consider whether maternal deaths alone still provide a valid measure of the mortality associated with reproduction in the community. If, for example, women take the pill and thereby do not become pregnant but die of vascular disease instead of the complications of pregnancy it would be misleading to conclude that the consequent reduction in maternal deaths necessarily represented an improvement in the overall mortality associated with reproduction. A more appropriate measure would be one which included deaths from

Department of Medical Statistics and Epidemiology, London School of Hygiene and Tropical Medicine, London WC1E 7HT

VALERIE BERAL, MRCP, lecturer in epidemiology adverse effects of contraceptives as well as those from complications of pregnancy.

I suggest that a new measure, reproductive mortality, be used to describe the mortality associated with reproduction in the community. It is defined as the total number of deaths each year due to $(a)$ spontaneous and induced abortion, $(b)$ complications of pregnancy, delivery, and the puerperium (other than abortion), and (c) adverse effects of contraception. I describe here the changes in reproductive mortality rates which have occurred in England and Wales since 1950.

\section{Sources of data and methods}

The Registrar General's Statistical Reviews for England and Wales provide data on the annual number of deaths from spontaneous and induced abortions (ICD 650-652, 6th and 7th revisions; ICD 640645,8 th revision) and all other complications of pregnancy, childbirth, and the puerperium (ICD 640-649, 653-681, 6th and 7th revisions; ICD 630-639, 646-679 8 th revision). ${ }^{1}$

The numbers of deaths associated with contraceptive use are not routinely available but can be estimated from data collated from various sources. I assumed that there was no mortality directly attributable to side effects of barrier methods, withdrawal, or variants of the rhythm method other than the risks related to accidental pregnancies. Such deaths and any deaths from accidental pregnancy associated with the pill, the IUCD, or female sterilisation would have been included automatically in the Registrar General's statistics on mortality from complications of pregnancy, delivery, and the puerperium.

The basic data used in this analysis are summarised in table I.

TABLE I-Estimated numbers of married women aged 25-34 and 35-44 in England and Wales who were using oral contraceptives or IUCDs in 1970 and 1975, or who underwent an operation for female sterilisation in 1960, 1970 and 1975. Estimated mortality rates associated with each method of contraception are shown

\begin{tabular}{|c|c|c|c|c|c|}
\hline \multirow[b]{3}{*}{$\begin{array}{l}\text { Method of } \\
\text { contraception }\end{array}$} & \multirow[b]{3}{*}{ Year } & \multicolumn{4}{|c|}{ Age } \\
\hline & & \multicolumn{2}{|r|}{$25-34$} & \multicolumn{2}{|r|}{$35-44$} \\
\hline & & $\begin{array}{c}\text { No. of } \\
\text { women } \\
\text { (in } 100000 \text { s) }\end{array}$ & $\begin{array}{l}\text { Associated } \\
\text { mortality }\end{array}$ & $\begin{array}{c}\text { No. of } \\
\text { women } \\
\text { (in } 100000 \text { s) }\end{array}$ & $\begin{array}{l}\text { Associated } \\
\text { mortality }\end{array}$ \\
\hline $\begin{array}{l}\text { Oral } \\
\quad \text { contraceptives }\end{array}$ & $\left\{\begin{array}{l}1970 \\
1975\end{array}\right.$ & $\begin{array}{l}4 \cdot 91 \\
8 \cdot 41\end{array}$ & $\begin{array}{l}4.4 \text { per } 100000 \\
\text { women per } \\
\text { year }\end{array}$ & $\begin{array}{l}2 \cdot 07 \\
3 \cdot 59\end{array}$ & $\begin{array}{l}33.0 \text { per } 100000 \\
\text { women per } \\
\text { year }\end{array}$ \\
\hline IUCDs & $\left\{\begin{array}{l}1970 \\
1975\end{array}\right.$ & $\begin{array}{l}1 \cdot 16 \\
1 \cdot 83\end{array}$ & $\begin{array}{l}0.3 \text { per } 100000 \\
\text { women per } \\
\text { year }\end{array}$ & $\begin{array}{l}0 \cdot 86 \\
1 \cdot 36\end{array}$ & $\begin{array}{l}0.3 \text { per } 100000 \\
\text { women per } \\
\text { year }\end{array}$ \\
\hline Ciorilioution & 1960 & 0.01 & $\begin{array}{l}25 \text { per } 100000 \\
\text { operations }\end{array}$ & 0.01 & $\begin{array}{c}25 \text { per } 100000 \\
\text { operations }\end{array}$ \\
\hline Sterilisation & $\left\{\begin{array}{l}1970 \\
1975\end{array}\right.$ & $\begin{array}{l}0.16 \\
0.14\end{array}$ & $\begin{array}{c}10 \text { per } 100000 \\
\text { operations }\end{array}$ & $\begin{array}{l}0 \cdot 10 \\
0.09\end{array}$ & $\begin{array}{l}10 \text { per } 100000 \\
\text { operations }\end{array}$ \\
\hline
\end{tabular}

The number of deaths from side effects of oral contraceptives and the IUCD were estimated from data on the prevalence of pill and IUCD use $e^{23}$ and from reports of the mortality related to their use. ${ }^{45}$ The numbers of women using the pill and IUCD were obtained from two surveys of randomly selected samples of married women in England and Wales; one survey was carried out in 1970, the other in $1975^{\circ}:$. The 1970 survey did not include women aged 41 years or older. I assumed that the prevalence of oral contraceptive and IUCD use at age 41-44 years was half that at age 40 . This should provide a reasonable estimate, albeit a slight underestimate, of contraceptive use at ages 40-44 years in 1970, since in 1975 the prevalence of oral contraceptive and IUCD use at ages 40-44 years was half that of the 35-39 year age group. ${ }^{3}$

The pill-associated morcality rates in women aged 25-34 and 35-44, shown in table I, were the excess mortality rates from circulatory 
diseases (ICD 390-464) in "ever-users" of oral contraceptives compared with "never-users", reported in the Royal College of General Practitioners' (RCGP) prospective study of women taking oral contraceptives. ${ }^{+}$Before estimating pill-associated mortality for England and Wales, I made the following assumptions: (1) The excess mortality from circulatory disease in "ever-users" of the pill in the RCGP study was applicable to "current users" of the pill. It should be noted, however, that "current users" had a higher mortality than "ever-users." (2) "Ex-users" of the pill in England and Wales had no excess mortality from circulatory disease, although there may in fact have been a residual increase in mortality. ${ }^{4}{ }^{6}$ (3) The excess mortality among pill users was confined to circulatory disease. There is evidence, however, of an increased risk of liver tumours, malignant melanoma, and cancer of the uterine cervix, and a decreased risk of ovarian cancer ${ }^{7-9}$ in pill-users, although the size of these effects has not yet been assessed. (4) The mortality of the RCGP study population was representative of that of the general population. In fact the RCGP population was healthier and its mortality lower than that of women of a similar age in England and Wales. ${ }^{4}$ (5) Data on pill use by single, widowed, and divorced women aged 25 to 44 years were not available, and since they constituted a relatively. small proportion of the population, I assumed here that there was no excess pill-related mortality among them. Had I assumed that their frequency of pill use was similar to that of married women, the estimated reproductive mortality rates would have been marginally greater than those presented in table II. (6) There was no error in the risk estimates from the RCGP study. The sampling variation was large, but the general conclusions would not have been materially altered even with considerable sampling error in the risk estimates. (7) The excess mortality from circulatory disease in women taking the pill was a direct effect of the pill.

TABLE II-Estimated reproductive mortality for women aged 25-34 and 35-44 in England and Wales in 1950, 1960, 1970, and 1975

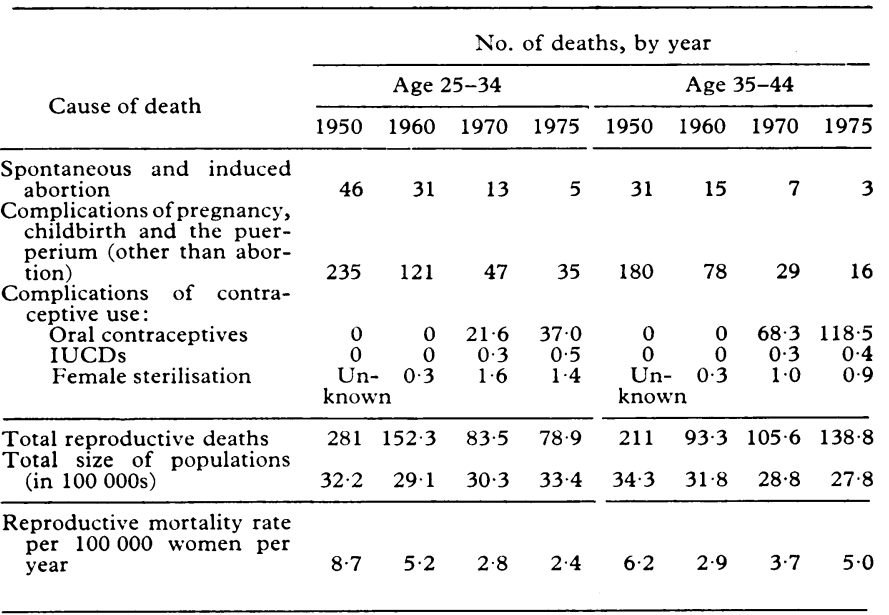

Assumptions (1) to (5) would lead to underestimates of pillassociated mortality. Assumptions (6) and (7) might overestimate or underestimate the risk, but independent data from 21 countries suggest that the changes in mortality coincident with the introduction of oral contraceptives were consistent with a direct effect of the pill and with a risk comparable to that found in the RCGP study. ${ }^{10}$ Because of assumptions (1) to (5) the figures in table II concerning pill-associated deaths would tend to be conservative estimates of the true numbers of deaths.

Mortality associated with the use of IUCDs has been reported by Kahn and Tyler. ${ }^{5}$ They found an annual excess mortality of 0.5 per 100000 women using these devices. Forty per cent of the deaths on which the mortality estimate was based were due to sepsis complicating an accidental pregnancy; but the remaining $60 \%$ were attributed to pelvic inflammatory disease or followed the removal of a translocated device and were unrelated to pregnancy. Since the deaths from complications of pregnancy were included in the Registrar General's statistics, the mortality estimate from adverse effects of the IUCD which were unrelated to pregnancy was thus $60 \%$ of 0.5 , or 0.3 per 100000 women per year. Because no age-specific data were available I assumed the mortality at ages 25-34 and 35-44 to be similar.
Deaths associated with sterilisation in women were estimated from the number of such operations performed each year in NHS hospitals, ${ }^{11}$ together with information on the reported operative mortality. Since some of the sterilisations were carried out in association with abortion or in the postpartum period and any related death would already be included in the Registrar General's statistics the data in table I exclude sterilisations carried out with abortion or delivery. As the age distribution of the women who were sterilised was available for 1968 and 1973 only, the numbers of operations in women aged 25-34 and 35-44 in 1960,1970, and 1975 were estimated by assuming that the 1968 age distribution applied in 1960 and 1970 and that the 1973 age distribution applied in 1975. During the 1960s the operative mortality rate was about 25 per 100000 operations, ${ }^{12}$ but in the $1970 \mathrm{~s}$ it fell to about 10 per 100000 operations. ${ }^{13} 14$ In the absence of further information, the operative mortality was assumed to be similar at ages 25-34 and 35-44, although mortality is likely to be higher in the 35-44 age group than at younger ages.

The reproductive mortality rate was calculated only for women aged 25-34 and 35-44 years. This is because data on the mortality associated with different methods of contraception, particularly oral contraceptives, are especially unreliable under the age of 25 : in the RCGP study there was one death from circulatory disease under the age of 25 . The numbers of deaths attributable to oral contraceptives, the IUCD and female sterilisation, calculated from the data in table I, are shown in table II, rounded to one decimal place. (The decimal point remains only to remind the reader that the numbers are estimated.)

\section{Results and comment}

Table II summarises the estimated reproductive mortality in women aged 25-34 and 35-44 years for the years 1950, 1960, 1970, and 1975 . The reproductive mortality rate was roughly halved between 1950 and 1960 in both age groups. After 1960 the estimated reproductive mortality rate continued to decline in women aged 25 34 years but increased in those aged 35-44 years.

There has been a remarkable and continuing downward trend in maternal mortality-that is mortality related to spontaneous and induced abortion and to other complications of pregnancy, childbirth, and the puerperium. In both age groups maternal mortality rates declined by more than $85^{\circ}$ over the 25 years since 1950 . On the other hand, after 1960 there was a large increase in mortality from adverse effects of contraceptives. This was almost entirely accounted for by the deaths related to oral contraceptive use. In 1975 , for example, there may have been no more than one extra death in women aged 25-44 resulting directly from a complication of IUCD use and two or three extra deaths from female sterilisation. Yet more than 150 deaths were estimated to be related to use of the pill. In women aged 25-34 the increase in pill-associated deaths was, however, more than balanced by the rapid decline in pregnancyassociated mortality, and so the overall reproductive mortality rate continued to decline over time. But there was a change in the relative importance of the various factors contributing to reproductive mortality: in 1975 about half the reproductive deaths in women aged 25-34 were from side effects of oral contraceptives and half were from complications of pregnancy.

In women aged 35-44 the increase in pill-associated mortality since 1960 exceeded the decrease in mortality from complications of pregnancy. This accounted for the increase in the estimated reproductive mortality rate since that time. In 1975 more than $85 \%$ of the reproductive deaths in women aged 35-44 may have resulted from adverse effects of the pill.

Deaths due to abortion were comparatively infrequent. In 1975 they accounted for no more than $7 \%$ of reproductive deaths at age $25-34$ and $2 \%$ of reproductive deaths at age $35-44$.

\section{Discussion}

The transfer from traditional to modern methods of birth control during the past 25 years has been accompanied by a transfer of deaths from complications of pregnancy to deaths from complications of the modern contraceptive methods. The transfer of deaths has resulted in a reversal of the relative importance of pregnancy-related and contraception-related mortality in the community. It is estimated that in 1975 more women aged 25-44 years died from adverse effects of the pill 
than from all complications of pregnancy combined (including abortion). Despite this the overall reproductive mortality rate has fallen continuously for women aged 25-34 years. This is because the decline in deaths from complications of pregnancy at this age has, on balance, been more rapid than the increase in deaths from complications of contraceptive use. Thus, from the public health point of view, women aged 25-34 are better off now than they were in the past. But women aged 35-44 years are worse off now: their reproductive mortality has increased since 1960. This is because of the relatively high pillassociated mortality at that age: in 1975 there may well have been more than seven times as many pill-related deaths as pregnancy-related deaths in women aged 35 to 44 years.

Maternal mortality should therefore no longer be regarded as an adequate indicator of women's health in relation to their reproductive practices. The reproductive mortality rate, which includes deaths from adverse effects of contraception as well as deaths from maternal causes, is a more appropriate measure. It is not ideal, however. It does not take into account associated morbidity, nor social or psychological factors, all of which are important in evaluating the health effects of different reproductive practices in the community. Nor can it be measured reliably at present. The reproductive mortality rates calculated here were estimated by combining information from many sources; the figures shown in table II should therefore be regarded as approximate only. The numbers of deaths associated with IUCDs or female sterilisation are so small that large errors in the estimates of the associated mortality rates or in the numbers of women using the methods would have little effect on the overall reproductive mortality rate. On the other hand, because of the relatively large number of pill-associated deaths, errors in their estimation might have substantial effects on the reproductive mortality rates. In women aged 25 to 34 years the progressive downward trend in mortality would be reversed only if the true pill-associated mortality were underestimated by more than threefold. And the upward trend in reproductive mortality in women aged 35 to 44 years would be reversed only if the true pill-associated mortality at that age were overestimated by more than twofold. Since most of the assumptions made in calculating the number of pill-associated deaths tended to underestimate the true number of deaths, it is unlikely that deaths in women aged 35 to 44 years are grossly overestimated. Thus it seems reasonable to conclude that-even though they are approximations-the general trends in reproductive mortality described here are adequate representations of true changes in reproductive mortality.

During this century there has been a spectacular decline in maternal mortality. Given the widespread use of effective but potentially fatal contraceptives today, we should now be aiming at reducing reproductive mortality in general as well as maternal mortality alone. The recommendations by the presidents of the Royal Colleges of Obstetricians and Gynaecologists and of General Practitioners in October 1977 that women over the age of 35 years who take the pill should consider using other methods of contraception ${ }^{1 ;}$ could, if followed, do much to reduce reproductive mortality in the future.

I thank Ms Margaret Bone for unpublished tabulations from her surveys; Dr Patricia Fraser, Ms Clair Chilvers, Dr Paul Fine, and Professor G Rose for their helpful comments; and Mr Richard Fine for the many valuable insights he provided.

\section{References}

${ }^{1}$ Registrar General's Annual Reports for 1875, 1950, 1960, 1970, and 1975, England and Wales. London, HMSO.

" Bone, M, Family Planning Services in England and Wales. London, HMSO, 1973.

${ }^{3}$ Bone, M, The Family Planning Services: Changes and Effects. London, HMSO, 1978.

* Royal College of General Practitioners, Lancet, 1977, 2, 727.

${ }^{5} \mathrm{Kahn}, \mathrm{H} \mathrm{S}$, and Tyler, C W, Fournal of the American Medical Association, 1975, 235, 57

${ }^{6}$ Petitti, D B, and Wingerd, J, Lancet, 1978, 2, 234.

' World Health Organisation, Steroid Contraception and the Risk of Neoplasia. Technical Report Series No 619. Geneva, WHO, 1978.

${ }^{8}$ Beral, V, Ramcharan, S, and Faris, R, British Fournal of Cancer, 1977, 36, 804

${ }^{9}$ Newhouse, M L, et al, British fournal of Preventive and Social Medicine, $1977,31,148$

"Beral, V, Lancet, 1976, 2, 1047.

11 Bledin, K D, Beral, V, and Ashley, J S A, Health Trends, 1978, 10, 84.

1.2 Presser, H B, Reports on Population-Family Planning. No 5. Population Council, New York, 1970

${ }_{13}$ Kleinman, R L, Male and Female Sterilisation. IPPF, London, 1973.

1 Royal College of Obstetricians and Gynaecologists, Gynaecological Laparoscopy: Report of the Working Party of the Confidential Enquiry into Gynaccological Laparoscopy. RCOG, London, 1978.

${ }^{15}$ Kuenssberg, E V, and Dewhurst, J, Lancet, 1977, 2, 757.

(Accepted 25 fuly 1979) 